\title{
La concepción del archivo en la sociedad de la información: PARES como motor del cambio
}

\author{
Javier RUIZ ASTIZ \\ Archivo General de la Administración \\ jruizastiz@gmail.com
}

Recibido: Septiembre 2012

Aceptado: Marzo 2013

\begin{abstract}
Resumen: PARES actúa como si se tratase de un único archivo virtual que pretende servir de referente para la difusión de nuestra cultura. El presente artículo pretende analizar la nueva concepción del archivo en la sociedad de la información. Primero se comprobará lo importante que es proceder a la digitalización de los documentos para tratar de conservarlos y publicitarlos. Posteriormente se hará mención al interés que despierta nuestra cultura a través del estudio de las tecnologías de la información y comunicación. En tercer lugar profundizaremos en la opción que supone para nosotros la difusión del patrimonio documental. Y por último, todo ello será argumentado en base a los datos que nos arroja el uso de la plataforma en los años que lleva en funcionamiento, comprobándose su rotundo éxito.
\end{abstract}

Palabras clave: Archivo digital; PARES; Acceso; Cultura; Usuario.

\section{The conception of archive in society of the information: PARES like motor of change}

\begin{abstract}
PARES act as if it was a unique virtual file that it tries to serve as referring for the diffusion of our culture. The present article tries to analyze the new conception of the file in the society of the information. First the important thing will be verified that it is to come to the digitalization of documents to try to conserve them and to spread them. Later mention to the interest will be made that wakes up our culture through study of the technologies of the information and communication. Thirdly we will deepen in the option that supposes for us the diffusion of the documentary patrimony. And finally, all this will be argued on the basis of the data that to us the use of the platform in the years throws that takes in operation, verifying itself its full success.
\end{abstract}

Keywords: Digital archive; PARES; Access; Culture; User.

\section{INTRODUCCIÓN}

En mayo de 2007, durante la presentación del proyecto que daba nacimiento a PARES, la ex-ministra de cultura, Carmen Calvo, señaló que esta herramienta debía "mejorar la gestión interna, la conexión y la coordinación de los archivos 
estatales, así como la accesibilidad y difusión de estos documentos hacia los ciudadanos". Sin duda, los primeros archivos virtuales están ya en funcionamiento tras haberse ido gestando en los últimos años ${ }^{2}$. Permitiéndonos algunos de ellos no sólo el acceso remoto a sus fichas descriptivas, sino incluso a buena parte de sus fondos porque algunos documentos se nos ofrecen ya en imágenes digitales. Debemos ser conscientes de que este nuevo paradigma implicará, antes que nada, nuevos servicios que se verán integrados en una novedosa filosofía centrada en interactuar con los usuarios. Un contexto que provocará que tengamos que asumir la cada vez mayor cercanía con la sociedad de la información, lo que hará que se oferten nuevos productos. Situación que modificará por completo el tiempo y el espacio para tratar de satisfacer las necesidades y demandas de los ciber-usuarios.

La unión de patrimonio documental y tecnologías de la información tiene importantes consecuencias en nuestro ámbito de actuación. En primer lugar, no debemos olvidar que la digitalización de los documentos se ha mostrado como un medio de conservación de suma eficacia. Aunque ello no quiere decir que resulte barato emprender proyectos de digitalización. Si bien se trata de una solución que hasta la fecha se ha convertido en una pauta hegemónica. Igualmente las nuevas tecnologías se erigen en un perfecto medio de difusión, puesto que amplifica las posibilidades de dar a conocer la existencia de un patrimonio. Favoreciendo, a su vez, la multiplicación de los posibles receptores, los cuales se podrán convertir en futuros usuarios. El camino está ligeramente esbozado, pero ahora es el momento de empezar a trazarlo de un modo ágil y firme. El futuro de los archivos como instituciones que albergan la memoria de cualquier sociedad pasa inexorablemente por la explotación de dichos documentos como contenidos accesibles a través de internet, lo que no hará que dejen de tener la consideración de bienes culturales.

El presente artículo surge fruto de la encrucijada en la que nos encontramos en estos momentos, lo que ha provocado que haya decidido optar por esta temática. Y más si tenemos en cuenta que los profesionales de los archivos debemos reparar en distintos aspectos, aunque todos ellos giran en torno a las repercusiones que la sociedad de la información está teniendo, y va a tener, en los centros de archivo. Las tradicionales preocupaciones que circundaban nuestra disciplina se han visto subsumidas en un magma mucho mayor, puesto que en la actualidad las nuevas tecnologías han originado una verdadera revolución en la concepción del archivo. Ello ha hecho que surjan nuevos problemas a los que debemos tratar de dar respuesta. Entre estos nos encontramos, primero, con la aparición del llamado archivo virtual. La sustitución del documento en papel por otros creados en formato electrónico está ocasionando multitud de quebraderos de cabeza para tratar de resolver

\footnotetext{
${ }^{1}$ HERNÁNDEZ OLIVERA, L., "La ley del deseo: un examen a las medidas adoptadas por el Gobierno para cumplir la ley de Restitución de documentos a la Generalidad". Archivamos, 63, 2007, p. 10.

${ }^{2}$ DE LA OSSA DÍAZ, F., "Reproducción de documentos y conservación del patrimonio documental". Boletín de la ANABAD, LII-3, 2002, p. 75.
} 
las incógnitas que encierran a los archiveros más tradicionales y apegados a los dogmas anteriores. Sin embargo, el contexto actual supone una verdadera oportunidad para dar a conocer nuestros centros a la sociedad. La difusión del patrimonio gracias a las nuevas herramientas que tenemos a nuestro alcance nos permitirá equipararnos con otro tipo de centros culturales, caso de las bibliotecas o los museos. ¿O acaso no podemos encontrarnos entre nuestros fondos con verdaderas piezas de un valor incuestionable?

En consecuencia, los fines que pretende alcanzar el presente estudio será llegar a demostrar que el archivo virtual, y más en concreto el Portal de Archivos Españoles, puede satisfacer las necesidades de la sociedad de la información. PARES ha sido impulsado gracias al beneplácito del Ministerio de Cultura y su decidida apuesta por las nuevas tecnologías ha propiciado la creación de esta magnífica herramienta que pretende no sólo confeccionar un medio mediante el cual difundir, publicitar y hacer accesible parte del Patrimonio Documental del Estado ${ }^{3}$, ya que al mismo tiempo trata de gestionar de un modo eficiente un servicio público de cara a la ciudadanía. Es por ello que se trata de mucho más que una mera plataforma de acceso a las fichas descriptivas y las imágenes de los documentos que se encuentran digitalizados en los distintos archivos y centros que pertenecen al sistema archivístico controlado por el Ministerio de Cultura. Nos encontramos ante un espacio que propicia la comunicación, el aprendizaje y la reflexión. Se trata de un sitio abierto a la sociedad, en donde los usuarios deben poder compartir sus inquietudes y aficiones, así como estar en contacto.

\section{DIGITALIZAR PARA CONSERVAR Y PUBLICITAR LOS DO- CUMENTOS}

Es conveniente estimular en la sociedad actual un afán por preservar de forma eficaz para que se pueda garantizar la conservación de la memoria de cada etapa histórica. La situación invita a emprender políticas archivísticas ambiciosas y modernas, centradas todas ellas en conseguir la perdurabilidad de un patrimonio que constituye el legado histórico que dejaremos a las futuras generaciones, así como a las actuales. Por lo que es necesario asegurar su acceso y difusión a través de las distintas tecnologías de la información y la comunicación. La idea fundamental es

\footnotetext{
${ }^{3}$ El patrimonio que gestiona PARES es el que se conserva en los once archivos de titularidad estatal: Archivo de la Corona de Aragón, Archivo de la Real Chancillería de Valladolid, Archivo General de Indias, Archivo General de la Administración, Archivo General de Simancas, Archivo Histórico Nacional, Archivo Provincial de Álava, Archivo Provincial de Guipúzcoa, Archivo Provincial de Vizcaya, Centro Documental de la Memoria Histórica y Sección Nobleza del Archivo Histórico Nacional.
} 
que se debe facilitar su consulta, con lo que lograr evitar la manipulación y el deterioro de unos documentos considerados como únicos e irrepetibles ${ }^{4}$.

Entre los objetivos de la digitalización se encuentra no sólo lograr conseguir la preservación de los documentos, sino también darles una mayor difusión entre la ciudadanía haciéndolos accesibles, e incluso ayuda a incrementar su valor social. Esta es una de las metas que persigue alcanzar cualquier proyecto de digitalización ambicioso. Ello debe permitir garantizar otro de los objetivos que suelen perseguir este tipo de actuaciones, que no es otro que informar a la ciudadanía cuando lo estimen conveniente. Facilitando, de este modo, el acceso y la consulta por parte de los usuarios ${ }^{5}$, bien sean éstos tanto externos como internos. Aunque bien es cierto que hay críticas en torno a la actitud adoptada hasta la fecha por los archiveros, ya que según Sebastià i Salat ${ }^{6}$, éstos se han dedicado a garantizar la disponibilidad de los documentos y se han olvidado de asegurar que resulten accesibles.

Pese a ello, la digitalización de documentos implica importantes ventajas a aquella institución que decide emprender una tarea de esta envergadura, puesto que le confiere una mayor accesibilidad y movilidad a sus documentos, así como una eficaz seguridad y control de todos ellos. A su vez, supone un considerable ahorro de espacio físico y de forma indirecta también se reducen gastos monetarios. No obstante, entre los aspectos positivos que acarrea un proyecto de digitalización debe remarcarse que detiene el deterioro, facilita la restauración de los documentos y amplifica la difusión de los mismos.

Para todo ello habrá que establecer una metodología de trabajo adecuada. Confeccionar un plan de digitalización es una premisa esencial para resolver los problemas concernientes a la salvaguarda de los documentos más interesantes y de la conservación más eficiente teniendo en cuenta el volumen tan ingente de documentación que se crea en la actualidad. Con esta planificación y programando el orden de actuaciones se logrará abordar de forma escalonada la digitalización y la restauración óptica digital de los documentos seleccionados. Los objetivos que se pretenden alcanzar con la digitalización son: optimizar las estrategias de preservación y difusión de los documentos, así como facilitar la divulgación de la documentación, permitiendo una eficaz consulta a la ciudadanía. Pero si queremos con-

\footnotetext{
${ }^{4}$ Como lo atestiguan ALBERCH, R., "Memoria, digitalización y mecenazgo", en El profesional de la información, 10-9, 2001, p. 35; BARROSO, A., "Archivos virtuales: ¿ya hemos llegado? El proyecto de digitalización del AHEB-BEHA". Letras de Deusto, 33-II, 100, 2003, p. 63.

${ }^{5}$ ESCALANTE JIMÉNEZ, J., "El Archivo Histórico Municipal de Antequera: conservación y perspectivas de futuro". Sociedad: Boletín de la Sociedad de Amigos de la Cultura de Vélez-Málaga, 4, 2005, p. 36; BESCÓS, J.; NAVARRO, J., "La digitalización como medio para la preservación y acceso a la información en archivos y bibliotecas". Educación y bibliotecas. Revista mensual de Documentación y recursos didácticos, 80, 1997, p. 41.

${ }^{6}$ SEBASTIÀ I SALAT, M., "Archiveros/Infotecnólogos: la Internet como motor del cambio de imagen de los archivos", en XII Jornadas de Archivos Municipales. El Archivo en el Entorno Cultural. Madrid, 1998, p. 91.
} 
seguir un proyecto de digitalización que resulte eficaz tendremos que seleccionar los documentos que serán objeto de los distintos procesos de transformación a formato digital. Para ello se procederá a designarlos siguiendo distintos criterios, caso de las diferentes etapas históricas de los documentos, su estado de conservación, su grado de consulta y su valor cultural.

No cabe duda que, la preservación digital, está conformada por un conjunto de actividades que pretenden asegurar el acceso continuado a documentos digitales, y más teniendo en cuenta que nos encontramos en una encrucijada en la que los elementos tecnológicos son rápidamente cambiantes. Las políticas de preservación requieren un máximo compromiso institucional. Por lo que un plan de preservación deberá contemplar la selección de materiales a preservar, el tiempo de conservación, las estrategias de recuperación, los esquemas de almacenamiento que los mantenga inalterados y el programa de renovación periódica. Es evidente el peligro que corre el patrimonio digital fruto de la obsolescencia de hardware y software, la incertidumbre de los recursos y los métodos de mantenimiento, así como la falta de definición de responsabilidades y legislación que proteja dicho patrimonio. No obstante, para tratar de garantizar la conservación de documentos digitales será conveniente proceder a la implantación de un sistema de gestión documental que sea integrado, controlado y normalizado. Debiéndose asegurar que los documentos sean fiables, auténticos e íntegros, y que se hallen correctamente descritos para ser identificados, conservados y recuperados de un modo eficiente.

Si nos detenemos por un instante en la realidad del Portal de Archivos Españoles, nos damos cuenta que no todos sus fondos se encuentran digitalizados. En la actualidad cuenta con 5.5 millones de unidades descriptivas que dan acceso a unos 26.5 millones de imágenes digitales. Pese a ello, se trata de una pequeña parte, pues queda mucho trabajo por delante si se quiere llegar a los $280 \mathrm{~km}$ de estanterías que albergan los archivos estatales. Bien es cierto que el ritmo de los últimos años ha sido paulatino, y que detrás de cualquier proceso de digitalización hay un trabajo previo de análisis, descripción y catalogación de documentos que entrañan distintas dificultades por su estado de conservación o por la propia escritura empleada en los materiales objeto de estudio. Por ello, como sugiere Sánchez Maire$\mathrm{na}^{7}$, no podemos quedarnos con la idea de que digitalizar es sencillo, ya que para proceder con dicha tarea hay que contar con anterioridad con bases de datos que permitan vincular nuestras fichas descriptivas a las distintas imágenes a las que den lugar.

Por lo general, la idea de proceder con la digitalización en cualquier archivo es poner a disposición de la sociedad el mayor número posible de documentos, pese a lo que debemos ser conscientes de que ello no es posible porque habrá que jugar con

${ }^{7}$ SÁNCHEZ MAIRENA, A., "Acercando los archivos a los ciudadanos. Una experiencia desde el Portal de Archivos Españoles (PARES) del Ministerio de Cultura". Arbor, 752, 2012, p. 11. (En prensa). 
criterios de selección. Una elección que, principalmente, vendrá marcada por la idea de conseguir preservar los documentos y permitir su difusión. No obstante, también es cierto que la selección de éstos se produce -como expone Sánchez Mairena ${ }^{8}$ - teniendo en cuenta determinados criterios de relevancia de acuerdo con los investigadores. Así se van produciendo de forma periódica cargas con nuevas descripciones en base a la $\operatorname{ISAD}(\mathrm{G})$ junto a imágenes digitalizadas para que sean consultables.

En definitiva, resulta muy positivo y encomiable el enorme interés demostrado por los miembros del Ministerio de Cultura por emprender un proceso de digitalización documental. Pero también debemos hacerles constar que los materiales digitales se ven acosados por diversos problemas, caso de la obsolescencia de la tecnología o su deterioro físico. Por lo que es necesario emprender la puesta en marcha de medidas que traten de garantizar la preservación y accesibilidad a un material que se encuentra en formato digital, no sólo para no perder parte del patrimonio estatal, sino a su vez, para amortizar la costosa inversión que se está llevando a cabo desde los organismos públicos.

No obstante, como bien hemos comprobado, no todo son aspectos negativos. Más bien al contrario, puesto que la digitalización supone una auténtica revolución en el sistema de consulta de los fondos archivísticos. Gracias a estas medidas no sólo se consigue tener unas búsquedas documentales mucho más prácticas y sencillas, sino también una consulta de los documentos más rápida, completa y eficiente. A lo que debemos añadir que las imágenes pueden ser tratadas por los usuarios para un mejor estudio, al igual que las pueden reproducir sin perjudicar el estado de conservación de dicho documento. En suma, la digitalización permite crear un nuevo modelo de objetos culturales con los que poder trabajar ${ }^{9}$, lo que sentará las bases de la cultura y el patrimonio digital. Pese a ello, como acertadamente lo sugiere Torres Freixinet ${ }^{10}$, debemos tener muy presente que las nuevas tecnologías nos abren un nuevo horizonte, pero también nos obligan a una constante renovación para estar al tanto de las nuevas herramientas existentes en el mercado. Todo ello es lo que conlleva ser partícipes en primera línea de las bienaventuranzas de la cultura digital.

\section{CIBERCULTURA AL ALCANCE DE LOS CIUDADANOS}

La revolución tecnológica que ha supuesto la irrupción de Internet ha provocado que la función social de los archivos se haya visto alterada, puesto que el acce-

\footnotetext{
${ }^{8}$ SÁNCHEZ MAIRENA, A., "El Portal de Archivos Españoles (PARES) como recurso para la historia local en internet". Canelobre. Revista del Instituto Alicantino de Cultura Juan Gil - Albert, 58, 2011 a, p. 77.

${ }^{9}$ ECHEVERRÍA, J., "Cultura digital y memoria en red". Arbor. Ciencia, Pensamiento y Cultura, CLXXXV, 737, 2009, p. 562.

${ }^{10}$ TORRES FREIXINET, L., "Preservación digital, el reto del futuro", MORALES GÓMEZ, J. (coord.), Actas de las VIII Jornadas de Archivos Aragoneses. Compartir Archivos, Vol. II. Huesca, 2008, p. 77.
} 
so abierto ha franqueado los muros físicos de estos centros custodios para abrir un espacio de interacción y comunicación social entre los usuarios ${ }^{11}$. Debemos tener muy presente que el acceso a la información es un derecho de todas las personas, por lo que es imprescindible garantizar el acceso a la misma a toda la ciudadanía. Es en este contexto en el cual la web se convierte en una herramienta con una enorme capacidad para lograr superar las barreras existentes, lo que le hace erigirse como un mecanismo ideal capaz de facilitar el acceso universal a los documentos que se encuentren disponibles.

Las nuevas tecnologías de la información han irrumpido en nuestra área dotándonos de unas mejoras evidentes en facetas como la conservación, difusión y gestión de los fondos que custodian nuestros archivos. A lo que debe añadirse el servicio tan eficaz que nos permiten dar a los usuarios. Estos recursos tecnológicos nos ayudan a crear sistemas de información archivística que lograrán mejorar el acceso de los ciudadanos a los documentos digitalizados y a sus descripciones ${ }^{12}$. Dicha realidad se consigue gracias a dos aspectos fundamentales; las bases de datos que facilitarán a los usuarios una rápida localización de los documentos y la consulta de las imágenes de los documentos tras la digitalización de éstos, preservándose así los documentos originales.

Para que los usuarios puedan decidir consultar nuestros fondos deben saber qué está a su alcance, pero para que esa divulgación se haga efectiva habrá que producir descripciones coherentes y que sean representativas de los documentos que pueden ser objeto de consulta. Sin esta opción el usuario pierde todo el poder que atesora, por lo que no tendrá conocimiento alguno sobre los documentos existentes y consultables, y ni mucho menos podrá conocer cuáles de aquellos se adaptan a sus necesidades ${ }^{13}$.

Sin embargo, de lo que no hay duda es que los centros de archivos se ven favorecidos por algunos de los aspectos que aportan las nuevas tecnologías. Entre los que deben ser destacados el incremento en el número de potenciales usuarios, pues no sólo han aumentado éstos y los accesos que ellos llevan a cabo, sino lo que es más importante, se ha conseguido garantizar su fidelidad. Tanto es así que la ciudadanía - como expone Cerdá Díaz ${ }^{14}$ - anhela un acceso integral a cualquier tipo de material sin tener en cuenta dónde se encuentren físicamente. Ello lo permite internet, puesto que la web ha evolucionado pasando de ser un recurso unidireccio-

${ }^{11}$ FERNÁNDEZ IZQUIERDO, F., "Fuentes primarias: la documentación archivística en Internet”, MALDONADO, A.; RODRÍGUEZ, L. (coords.), La información especializada en Internet. Madrid, 2006, p. 387.

${ }^{12}$ BESCÓS, J.; NAVARRO, J., "El documento histórico y el impacto de las tecnologías de la información”, Congreso Internacional sobre Sistemas de Información Histórica. Álava, 1997, p. 103.

${ }^{13}$ PIRES DE LIMA, M. J., "DIGITARQ: del archivo digital al usuario". Tabula, 8, 2005, p. 45.

${ }^{14}$ CERDÁ DÍAZ, J., "Archivos locales en la web. El futuro en la red", MORALES GÓMEZ, J. J. (coord.), Actas de las VIII Jornadas de Archivos Aragoneses. Compartir Archivos, Vol. II. Huesca, 2008, p. 163 . 
nal a multidireccional. Tanto es así que el contexto actual ayuda para la apertura de nuestros archivos, auspiciando una participación fluida de los usuarios, e incluso alentando actitudes de corte cooperativo. Aunque debemos indicar que el futuro pasará por la autogestión de los propios usuarios. Estos últimos decidirán qué desean demandar y cuándo requieren la información.

El archivo virtual ha supuesto un cambio radical en el comportamiento que manifiestan los usuarios. Lo que se debe a la aparición de nuevos servicios que han cambiado el panorama de nuestra disciplina. Unido a ello habrá que tener en cuenta que las tecnologías de la información han propiciado que los archivos se lancen a la caza de nuevos usuarios. Unas demandas totalmente distintas a las que hasta ahora estábamos acostumbrados, pero que sin ningún género de duda se están consolidando. Es por ello que debemos hablar del cambio de roles, pasando del usuario presencial al consumidor de cultural digital, o lo que es lo mismo a la existencia del usuario virtual. Una figura que con el paso de los años se convertirá en hegemónica.

En la sociedad actual, el reconocimiento y la visualización de los archivos como custodios de buena parte del patrimonio de cualquier Estado resultan elementales. Por ello debemos de ser capaces de abrirnos a la sociedad para que comprendan que el archivo no sólo juega un papel destacado en la construcción de nuestra memoria, sino que también supone una extraordinaria oportunidad para fomentar el consumo cultural. Atrayendo para ello a cualquier tipo de ciudadano, con lo que romper los viejos estereotipos de unos centros a los que únicamente se acercaban los profesores e investigadores del campo universitario.

No cabe duda de que los archivos deben encargarse de satisfacer las necesidades específicas de los usuarios si quieren proyectarse a la sociedad como centros culturales, y más desde que la propia ciudadanía empieza a demandar unos mejores servicios para poder acceder al patrimonio cultural. Lo que se está experimentado porque se ha producido una asimilación rápida de los beneficios que entraña el uso de las nuevas tecnologías para la propia ciudadanía, por lo que se han acostumbrado a usar estas herramientas para saciar sus apetencias ${ }^{15}$. Muestra inequívoca de la evolución de nuestra sociedad en un entorno altamente dependiente de las tecnologías y que ha dado lugar al nacimiento de lo que podemos entender como "ocio culto".

En definitiva, Internet se ha erigido como el vehículo preferente para transmitir el conocimiento gracias a que permite que este proceso se haga con suma rapidez. $\mathrm{Si}$ bien los contenidos aumentan de forma considerable, imposibilitándose conocerlos en su totalidad. A lo que debemos unir la dificultad que entraña solventar ciertas cuestiones, caso del modo en que se organizan esos contenidos para que resulten localizables de forma intuitiva, puedan ser accesibles y sean de utilidad para los demandantes de información. No obstante, ante la necesidad de localizar y ofertar

${ }^{15}$ RIVAS FERNÁNDEZ, J. B., "La sociedad del ocio: un reto para los archivos". Códice, 2-2, 2006, p. 79. 
información de forma controlada fueron apareciendo paulatinamente los portales. Siendo su objetivo erigirse como el referente de mayor calidad existente en la red para satisfacer las necesidades de sus distintos usuarios.

Cada portal suele estar destinado a unos determinados usuarios. Esos serían los portales especializados que se centran en una materia concreta para satisfacer las necesidades informativas de ciertos demandantes, sean profesionales o no. Mientras que la idea de los portales de archivos es ofrecer recursos destinados a una amplia gama de usuarios como sus potenciales consumidores de información. Siendo clave en todos ellos la gestión de sus contenidos y la forma en la que el usuario accede a los mismos. Para ello es imprescindible planificar adecuadamente el diseño del portal. La arquitectura de la información es la disciplina que se ocupa del planteamiento de las sedes web en la world wide web. Se trata de un conjunto de conocimientos, máximas, principios y técnicas que rigen la práctica de los que desarrollan y gestionan sus contenidos, y que ayudan a los usuarios a encontrar lo que buscan.

Pese a todo ello, ¿hacía dónde caminan los archivos virtuales? En los últimos años han ido surgiendo nuevas realidades que han trastocado nuestra disciplina, y lo más importante, incluso en la actualidad se van gestando cambios profundos en el modo de entender internet. Ello ha provocado, por ejemplo, que hace unos años haya surgido un movimiento que propugna conseguir la disponibilidad universal del corpus documental, sin ningún tipo de restricciones tecnológicas. Se trata del movimiento de acceso abierto, el cual también está tratando de expandirse hacia los archivos. La base de este movimiento es que propugna la disponibilidad de los documentos, concretándose ésta en ciertos aspectos:

- Disponibilidad electrónica: determinados documentos deben tener una versión electrónica disponible en alguna máquina que esté conectada a Internet.

- Disponibilidad sin restricciones técnicas: que se encuentren disponibles desde cualquier ordenador conectado a la red a través de un acceso sencillo y utilizando herramientas estándares.

- Disponibilidad 24 horas al día, sin restricciones de horarios.

- Disponibilidad para que terceras partes, como los agregadores de contenidos, aporten valor añadido, caso del desarrollo de motores de búsqueda o de clasificaciones que permitan navegar por los documentos.

En definitiva, disponibilidad libre, para todos y para siempre. Y más teniendo en cuenta que se estima que el impacto de nuestro patrimonio será mayor cuanto mayor sea el número de posibles demandantes de información. Es importante que puedan acceder a los documentos el máximo número de ciudadanos, lo que se conseguirá gracias a un interfaz OAI-PMH (Open Archives Initiative-Protocole for Metadata Harvesting). Un sistema que nos garantizará la interoperabilidad de cualquier depósito con otros de la misma naturaleza. 
Dicho proceso está a punto de iniciarse en PARES con la conversión del portal a un sistema de archivos abiertos en el ámbito de APEnet. Sin duda, las exigencias de poder interoperar con los distintos proyectos de difusión del patrimonio documental que existen en el seno de la Unión Europea han acelerado este cambio. Lo que supone abandonar la concepción que se tenía hasta ahora del portal, anclado en el modelo de la web 1.0, para tender hacia la filosofía OAI-PMH. Aunque debemos destacar que para la consecución de este ambicioso reto fijaron su atención -como indica Sánchez Mairena ${ }^{16}$ - en conseguir una integración normalizada de toda la información que estuviese disponible en la plataforma. Gracias a ello, se ha conseguido coordinar los procesos de transferencia de contenidos, datos e imágenes procedentes de PARES hasta APEnet, y en un futuro se podrá aplicar a otros repositorios de carácter OAI.

Junto a ello, la web 2.0 ha supuesto la apertura de nuevos escenarios a la sociedad gracias a las opciones que ha puesto de manifiesto en el actual marco cibernético. Se trata de una nueva manera de relacionarse a través de Internet, lo que sin duda alguna ha provocado un cambio en las reglas del juego. La idea de la web 2.0 es que los propios usuarios sean capaces de colaborar y compartir información de su interés a través de la red. Se trata de una nueva forma de interacción social. Los cambios que supone esta nueva forma de entender Internet son: accesibilidad, usabilidad, interoperabilidad, arquitectura de información colaborativa y multimedia.

Su principal novedad es que los usuarios pasan a ser una parte primordial de los procesos de información, dejando a un lado su pasividad. Sin ellos, la web, dejaría de tener sentido. Cualquier usuario utilizará la web como si de una aplicación se tratase. Se trata de aprovecharse del conocimiento colectivo que surge de las distintas aportaciones dadas por los usuarios, lo que facilita la creación de comunidades virtuales. Por tanto, el aspecto más llamativo de la web 2.0 es su naturaleza participativa. Con ella no sólo se dedican a leer y consultar los contenidos que ofrece un sitio web, sino que se encargan de discutir, comentar, opinar, anunciar, enlazar, publicar, intercambiar y compartir. Como puede apreciarse su participación es sumamente activa, aunque la idea es que los usuarios puedan sacar la máxima rentabilidad a sus consultas a través de la red.

Dentro de las herramientas que pone en funcionamiento la web 2.0 hay que destacar que la aplicación de los canales RSS por parte de PARES constituye el primer paso en busca de este nuevo modelo de concebir la red. Así RSS (Really Simple Syndication) es una herramienta a través de la cual podemos ofrecer cierta información que puede ser de interés para los internautas. Gracias a él, cualquier usuario que se haya suscrito a este sistema podrá conocer al instante todas aquellas

${ }^{16}$ SÁNCHEZ MAIRENA, A., "Nuevos retos en PARES (Portal de Archivos Españoles): interoperabilidad, normalización y calidad descriptiva y eficiencia del acceso al patrimonio archivístico digital español", VV.AA. (eds.), Actas del seminario internacional el futuro de la memoria: el patrimonio archivístico digital. Santiago de Compostela, 2011b, p. 791. 
novedades que hayan ido surgiendo en el Portal de los Archivos Españoles sin necesidad de tener que visitar la web ${ }^{17}$. Estas nuevas aplicaciones permiten a los demandantes de información utilizar y compartir los contenidos que han sido publicados, además de conocerlos de un modo rápido y eficiente. Igualmente los RSS de PARES facilitan a los suscriptores de este sitio web el acceso y la difusión de un listado de artículos procedentes de los destacados y las novedades, junto con resúmenes y enlaces hacia los artículos completos de esta web. Por tanto, RSS es la diferencia entre estar informado a través de internet y no estarlo, ya que su finalidad es mejorar la conexión con la sociedad.

Es por ello que, implementar la opción de trabajar con RSS ayudará a los usuarios a que empleen un menor tiempo en sus búsquedas para ponerse al día sobre materias de su interés, con lo que podrán evitar la consulta de distintos sitios web para satisfacer sus demandas. No cabe duda que sus potencialidades son enormes, y más cuando se decide emprender una investigación concreta, puesto que cabe la posibilidad de que se puedan suscribir a lugares determinados y ser informado de las novedades en cuanto éstas se experimentan. Además será un elemento de crucial importancia cuando se decidan crear comunidades virtuales de usuarios interesados en ciertas áreas, con lo que todos ellos podrán compartir e intercambiar información de forma rápida.

Asimismo, como sugiere Muñoz ${ }^{18}$, esta herramienta se está mostrando como un elemento de enorme peso en las instituciones que deciden aplicarlas a sus páginas web porque encierran numerosas ventajas tanto para la organización como para sus usuarios. Las ventajas para el Portal de Archivos Españoles serán:

- Utilidad: los contenidos web cambian constantemente.

- Funcionalidad: su uso cumple los fines comunicativos que debe satisfacer toda organización con sus posibles usuarios.

- Difusión: se trata de una herramienta para dar a conocer los recursos del portal de los archivos españoles.

En otro orden de cosas, existen ventajas para los propios usuarios. De todas ellas deben ser señaladas:

- Desaparece la preocupación por estar al tanto de las novedades que se vayan produciendo en el seno de una web, puesto que se encarga de actualizarlas de forma automática.

- Permite que el usuario sea quien decida dónde suscribirse, qué contenidos temáticos son de su interés y la regularidad con la que desee consultarlos.

\footnotetext{
${ }^{17}$ HUIDOBRO, J. M., "La sindicación web: RSS”. Bit, 167, 2008, p. 60.

${ }^{18}$ MUÑOZ, P., "Implementación del formato RSS en procesos de gestión y comunicación electrónicos en instituciones educativos, públicas y empresariales". Pixel-Bit, 31, 2008, p. 5.
} 
- Disponibilidad de los contenidos de un modo rápido e inmediato.

- Información constante porque las áreas temáticas que el usuario demanda son actualizadas en cortos períodos de tiempo.

- Se evitará la recepción de un número ingente de correos electrónicos, evitándose así la saturación de su bandeja de entrada.

- Posibilita incorporar los contenidos deseados a los blogs personales de los distintos usuarios.

- Ofrece la opción de publicitar o difundir las novedades existentes a través de las redes sociales, caso de Facebook o Twitter.

En suma, PARES debe utilizar su canal RSS como fuente de información para sus propios productos y servicios, haciéndolos más atractivos al mismo tiempo. Aunque no es menos relevante que, gracias a ello, conseguirán hacerlos mucho más visibles para un rango de usuarios mayor. Todo ello, mientras ofertan el portal para satisfacer de la mejor manera posible las distintas demandas de cada tipo de usuarios. Mientras que, por otro lado, servirá para fortalecer -como sugiere Sánchez $^{19}$ - la autonomía de los usuarios para que ellos decidan que escogen y seleccionan en todo momento. A la vez que les sirve para ahorrar tiempo de navegación y conexión.

Por último, el vector clave de la web 2.0 es que el propio ciudadano es quien se encarga de surtir de contenidos al resto de usuarios. Estamos hablando de un marco mucho más real y humano porque la red se convierte en un medio al servicio de las demandas de la propia sociedad. Es aquí donde nace la idea de implementar una comunidad virtual para PARES, ya que ésta sería eficaz por múltiples moti$\operatorname{vos}^{20}$. La principal es que la distancia física desaparece, permitiendo a sus miembros tener una comunicación fluida en todo momento, a sabiendas que de no ser por las nuevas tecnologías este medio no existiría.

Es importante que proyectos como el de PARES impulsen la creación de comunidades virtuales, ya que ello supondría configurar un espacio en el que los usuarios pudiesen compartir experiencias e intereses. El salto que estriba entre un portal y la comunidad es que en esta última los usuarios pueden interactuar entre ellos mismos, e incluso con los creadores de la propia comunidad. Un contexto en el que el profesional de los archivos debería tratar de responder a las demandas, sugerencias o reclamaciones de los usuarios.

Resulta conveniente que tengamos siempre muy presente que en la sociedad actual el ocio desempeña un papel elemental. La cultura se ha convertido, más que nunca, en un pasatiempo sumamente consumido por los ciudadanos, sean cuales

${ }^{19}$ SÁNCHEZ, N., "Sindicación de contenidos con canales RSS: aplicaciones actuales y tendencias". Acimed, 15-3, 2007, p. 3.

${ }^{20}$ Es un proyecto que ya se puso en marcha hace unos años pero se tuvo que interrumpir por el mal uso que algunos usuarios hacían de la herramienta. 
sean sus pretensiones. El tiempo que se dedica al esparcimiento personal es cada vez mayor y sus variantes son muy diversas, pero entre ellas se encuentra la cultura digital. No cabe duda que estar informado es un elemento clave que ayuda a mejorar la calidad de vida de la ciudadanía, y más en el contexto en el que nos encontramos. En el imaginario social el acceso generalizado a la cultura supone un valor añadido para la sociedad de un determinado lugar.

Es aquí donde entra el fenómeno de la web 2.0, y sobre todo si tenemos en cuenta que se trata de un profundo cambio en los modos de comunicarnos y relacionarnos entre nosotros, por lo tanto se trata de un cambio de raíz social por sus implicaciones para los usuarios, en donde compartir y participar son los ejes clave de este proceso $^{21}$. Debido a ello, es imprescindible que PARES emprenda el camino de la adopción de herramientas colaborativas que permitan la interactuación con los usuarios del portal. Lo que hará que, además de sus funciones primigenias, termine siendo un medio de comunicación al servicio de la sociedad. Tanto es así que, las ideas más relevantes en los procesos de aprendizaje con el soporte de la herramienta de PARES son las múltiples posibilidades que ofrece porque:

- Estimula la construcción de un discurso que resulta necesario para el desarrollo intelectual de las personas.

- Ayuda y enseña a localizar de forma correcta la información, además de seleccionarla para extraer de ella lo más relevante.

- Da la oportunidad de investigar y profundizar, desde el punto de vista del manejo de datos y de acceso a la información, según los conocimientos e intereses de cada usuario, así como de las fuentes y los recursos que se encuentren a su disposición.

- Es una herramienta que prioriza el trabajo personal, fomentando a su vez, la autogestión en el proceso de aprendizaje y asimilación personal.

- Permite abrir el trabajo de campo más allá de las salas de investigadores de los centros de archivos, al igual que favorece una docencia a distancia desde las propias aulas de las escuelas o las universidades. El usuario decide cuándo y dónde hace uso de los recursos existentes.

- El uso de las tecnologías como un medio interactivo y participativo propicia que se originen novedosas formas de intercambio y debate de ideas que llevan a los usuarios a la adquisición de conocimiento.

Por ello, debe quedar claro que adoptar la filosofía web 2.0 permitirá abrir los archivos virtuales a la participación de los usuarios. Lo que contribuirá a que éstos ya no sean meros receptores de información, sino que tras recibirla y procesarla, tendrán la opción de opinar mostrando su parecer al respecto. Así cualquier usuario pasará a tener las riendas al poder decidir, por medio de sus votos o visitas, qué

${ }^{21}$ IGARZA, R., Burbujas de ocio. Nuevas formas de consumo cultural. Buenos Aires, 2009, p. 93. 
noticias son las más relevantes para que se muestren entre las primeras en los motores de búsqueda. A lo que se unirá la posibilidad de que ellos mismos sean capaces de modificar los contenidos que se difundan para que todo redunde en beneficio de la colectividad. Este es el camino que ha decidido emprender PARES. Su planteamiento es mejorar el acceso a la información, pero principalmente tratar de satisfacer las demandas ciudadanas. Esto último resultará una pieza clave en el engranaje de nuestra disciplina en las próximas décadas, puesto que conseguir que nuestros usuarios nos sean fieles dependerá, en buena medida, de que nosotros seamos capaces de dar respuesta a sus necesidades, por lo que mejorar los servicios ofertados se erige como una tarea ineludible.

\section{DIFUSIÓN Y FORMACIÓN DE LA SOCIEDAD}

Superados ya los viejos estereotipos sobre los archivos se alza ante nosotros una nueva realidad que trata de concebirlos como garantes de la difusión del patrimonio cultural que albergan. Existiendo una estrecha relación entre el proceso educativo de cualquier ciudadano y el patrimonio documental. Así, por ejemplo, los recursos que ofrecen algunos archivos virtuales contribuyen a mejorar la docencia, haciéndola más entretenida y sugerente, pero sobre todo mucho más veraz debido al uso de documentos originales procedentes de distintas etapas históricas ${ }^{22}$.

No cabe duda de que los documentos que se encuentran en cualquier archivo resultan cruciales para toda sociedad. Su utilidad está ya perfectamente demostrada, aunque en estos momentos nos encontramos ante una gran oportunidad para hacer mucho más visibles nuestros centros dentro del patrimonio del devenir humano. Y más teniendo en cuenta las enormes posibilidades que nos ofrece la denominada como sociedad del conocimiento. Luchar porque nuestro trabajo diario tenga un reconocimiento a nivel cultural y social resulta elemental, puesto que así cualquier persona podrá servirse de nuestros servicios para ampliar sus conocimientos o satisfacer sus inquietudes ${ }^{23}$.

En estos momentos los archivos deben incentivar la creación de actividades, pero no para dar a conocer el archivo, sino para satisfacer las necesidades e intereses de los ciudadanos, pues de esta forma se conseguirán nuevos usuarios. Ello facilitará el hecho de que los centros de archivo sean mucho más perceptibles a ojos de la ciudadanía de cualquier país, puesto que en la actualidad todo servicio cultural que no es visible para la sociedad tiende a ser denostado y arrinconado. De la configuración de buena parte de esas actividades deben aprovecharse la escuela

${ }^{22}$ ANGULO MORALES, A., "Algunas reflexiones sobre los recursos de archivos históricos en Internet y en la enseñanza de la Historia”. Hispania, LXVI, 222, 2006, p. 38.

${ }^{23}$ ANORVE GUILLÉN, M. A., "Archivos y sociedad". Revista general de información y documentación, 17-2, 2007, p. 125. 
y la universidad. La idea que debe girar en torno a estas medidas es que resulta necesario difundir y promover el patrimonio documental existente en los archivos.

Para hacer posibles estos deseos debemos contar con la inestimable colaboración de las tecnologías de la información y comunicación. Gracias a ellas se están reduciendo de forma considerable las barreras de acceso a los documentos, ya que tradicionalmente entre los motivos que provocaban el alejamiento entre los centros docentes y los archivos nos encontrábamos con las dificultades que entrañaba acceder a las fuentes primarias dada la lejanía física, los horarios de apertura, la accesibilidad, el estado de conservación de los documentos o la tipología de letra de éstos. Por lo que debemos ser conscientes, cuanto antes, de que Internet nos abre un nuevo horizonte al permitirnos romper con aquella imagen de espacio cerrado y lejano, a la vez que nos garantiza un nuevo medio de acceso y difusión a los servicios que ofertan nuestros centros de archivo.

Las nuevas tecnologías, y más si nos amparamos en el caso de PARES, permiten que la investigación en las aulas sea posible. De esta manera se puede tejer un diálogo fluido entre los profesores y los alumnos. Pero lo más importante es que ello redundará en beneficio de los propios estudiantes, e incluso de la sociedad. Este modelo educativo fomentará que los alumnos adquieran unas capacidades cognitivas y espaciales que les ayudarán a investigar, aunque también hará que sean mucho más críticos, sagaces y responsables. Es evidente que nuestro patrimonio es único para lograr enseñar a los estudiantes, bien sean de secundaria o de universidad, para que puedan adquirir ciertos conocimientos. Entre los que pueden ser destacados:

- Enseñar a investigar y aprender.

- Conocer el pasado para tratar de educarles en la comprensión del presente.

- Formarles en el desarrollo y la adopción de habilidades cognitivas.

- Describir la relación entre lo global y lo local, entre los grandes hechos de la historia y los del ámbito municipal.

- Educarles para que sean capaces de valorar y disfrutar del patrimonio cultural.

- Hacerles partícipes en la defensa, conservación y difusión del patrimonio documental.

Ello hará que puedan percibir el patrimonio existente en los archivos estatales como testigos únicos capaces de construir el conocimiento de las nuevas generaciones. Abogando siempre por inculcarles una actitud de respeto por las distintas culturas y su respectiva simbología ${ }^{24}$. Entre los objetivos anhelados nos encontra-

${ }^{24}$ ESTEPA JIMÉNEZ, J., "El patrimonio documental y los archivos como recursos en la enseñanza de las ciencias sociales", REY DE LAS PEÑAS, R. (dir.), Aprender y enseñar con el archivo. Huelva, 2004, p. 39. 
mos con el fundamental, hacer que los fondos de los centros de archivo sean accesibles a todos. Para ello será imprescindible desarrollar unas herramientas e instrumentos que posibiliten que los usuarios sean capaces de ser autosuficientes. Siendo ellos quienes ostenten la autonomía suficiente para decidir qué quieren consultar por sus propios intereses. La idea es crear usuarios libres para poder elegir y pensar. Como acertadamente expone Cerda Díaz ${ }^{25}$, uno de los factores que juega en nuestra contra es que la ciudadanía nos aprecie como algo alejado de sus pretensiones por desconocimiento y desconfiar de sus capacidades.

Somos conscientes de que la digitalización de los documentos y su puesta en conocimiento a través de Internet ha originado un nuevo modo de investigar y de enseñar. Se debe explotar el enorme potencial que estos recursos tienen para la enseñanza en las escuelas y en las propias universidades. Y más teniendo en cuenta las opciones que nos ofrecen las nuevas tecnologías. Algo que ya han comenzado a aprovechar los gobiernos de Inglaterra y los Estados Unidos. Bien es cierto que PARES, como motor del cambio, da la oportunidad de disponer de textos de apoyo para la docencia en historia en la enseñanza secundaria, incluyéndose algunas transcripciones que acompañan a las imágenes de los documentos. Lo que supone algo más que una simple exposición virtual de documentos, puesto que este proyecto también tiene pretensiones didácticas para la sociedad.

Este propósito se pretende alcanzar, por ejemplo, con los distintos micro-sitios que son ofertados en el portal. En la actualidad nos encontramos con siete de estos espacios: 1/ Movimientos migratorios iberoamericanos; 2/ Víctimas de la Guerra Civil y Represaliados del Franquismo; 3/ El sello medieval; 4/ Colección digital de mapas, planos y dibujos del Archivo General de Simancas; 5/ Guerra de la Independencia; 6/ Archivo fotográfico de la delegación de propaganda de Madrid durante la Guerra Civil; 7/ Catastro de Ensenada. Ello se debe a que, dentro de la dinamización cultural que deben emprender los archivos, tienen que permitir la visita virtual a los materiales con los que cuentan en su interior. Organizándose para ello, distintos tipos de actividades que estén en relación con el archivo, caso de exposiciones virtuales o trabajos-juegos de carácter educativo y pedagógico. Esa es la finalidad de estos espacios. Se trata de otro nivel de información dentro de PARES que busca ofertar una visión detallada de un suceso o etapa de la historia a través del uso de imágenes digitalizadas, videos explicativos o la transcripción de textos medievales o modernos. Estamos, por tanto, ante un instrumento de cariz divulgativo que pretende instruir a la sociedad de un modo virtualizado.

Las autoridades deben ser conscientes del enorme potencial que tienen los archivos para incentivar en la propia sociedad un interés por la cultura que se encuentra depositada en sus fondos. Para ello es conveniente, no sólo que se dedi-

${ }^{25}$ CERDA DÍAZ, J., "Archivos y educación en la era digital. Nuevas vías de acceso y difusión para los servicios de archivo", REY DE LAS PEÑAS, R, (dir.), Aprender y enseñar con el archivo. Huelva, 2004, p. 57. 
quen a organizarlos y conservarlos, puesto que difundirlos resulta crucial en estos momentos, por lo que hay que aprovechar los beneficios que ponen a nuestro alcance las tecnologías de la información y de la comunicación. Sacando del olvido y la oscuridad a los depósitos archivísticos.

Entre los anhelos que pretende alcanzar un proyecto como PARES, y con ello, los que deberá satisfacer cualquier archivo virtual nos encontraremos con los siguientes aspectos:

- Estimular el conocimiento del patrimonio documental.

- Dotar de caracterización a las culturas a partir de los fondos existentes en los archivos.

- Promover procesos de identidad individual y colectiva gracias al patrimonio documental.

- Edificar una memoria individual y colectiva que tome en consideración los bienes y valores de la producción documental.

- Fomentar actitudes y valores que vayan encaminados a conocer y respetar todo testimonio documental existente en cualquier cultura pasada y presente.

- Incentivar el conocimiento de las culturas del pasado a partir de sus vestigios documentales.

La nueva concepción del archivo como un espacio virtual en donde ofertar el acceso a la información y la difusión del patrimonio documental nos debe hacer partícipes de una serie de medidas que deben ser promovidas para conseguir dar respuesta a los servicios que sean solicitados por los usuarios, así como aquéllos que, aunque no sean demandados de forma expresa, todo archivo debe tratar de implementar. Nuestros cometidos tienen que focalizarse ante un amplio espectro poblacional para poder dar respuesta a las nuevas exigencias de la ciudadanía. Así pueden ser distinguidos tres grupos de usuarios a los que la formación y la difusión del patrimonio debe ir dirigida:

- Ciudadanía o público en general. Es conveniente dar a conocer la existencia del propio archivo a todos los ciudadanos, diseñando productos y servicios para ellos. La diversidad de este público hará conveniente organizar diversas opciones en la web: visitas y exposiciones virtuales, cursos formativos (sobre paleografía, por ejemplo), o tutoriales de manejo de la herramienta.

- Mundo educativo (tanto enseñanzas medias como superiores). Se trata de un segmento poblacional al que se le puede ofertar unas opciones de aprendizaje muy atractivas. Principalmente pueden aprender mucho del manejo de fuentes primarias de información, caso de los documentos, pero también del uso de herramientas electrónicas como bases de datos y bus- 
cadores. Gracias a ello, el archivo se convertirá en un instrumento pedagógico conectado con las nuevas generaciones. Confeccionándose un vínculo entre los archivos y la sociedad que redundará en beneficio de todos.

- Investigadores tradicionales. Para ellos se orientan las acciones que se encaminan tanto a los que proceden del mundo académico (profesores de universidad), como a los que conforman un grupo heterogéneo de usuarios que deciden acceder a los fondos de archivos por interés personal, lo que podría denominarse como los investigadores aficionados. Para agilizar su trabajo y que les resulte mucho más eficiente requieren de útiles servicios a su alcance. Entre ellos, cabe resaltar la existencia de descripciones pertinentes, puesto que gracias a ellas podrán decidir si consultar unos documentos $\mathrm{u}$ otros.

El carácter de los archivos que conforman la red estatal debe hacer que sus servicios giren en torno a la sociedad, por lo que PARES debe tener presente que los usuarios son su principal referente. Es por ello que todas sus actuaciones y las medidas que se decidan emprender deberán tener en mente la utilidad por parte de la ciudadanía. Debemos ser conscientes que nuestros valedores son ellos, en consecuencia, las acciones que se lleven a cabo tendrán que diseñarse en base a éstos. Junto a ello, todas las medidas que se pongan en marcha tratarán de consensuar dos objetivos: por un lado dar a conocer nuestros productos y servicios, y por otro implementar las soluciones adecuadas para satisfacer las necesidades y los intereses de los usuarios. Una y otra van unidas, puesto que sin publicitarnos y aproximarnos a los internautas no tendrán conocimiento de nosotros, por lo que gracias a nuestra visibilidad en sociedad sabrán si desean consultar los fondos de un archivo o no.

\section{EFICACIA Y RENTABILIDAD DEL ARCHIVO DIGITAL: ANÁ- LISIS DEL ÉXITO DE PARES}

¿Resulta rentable PARES? El objeto del presente apartado es intentar medir el éxito del Portal de los Archivos Españoles para demostrar el rotundo éxito que ha tenido en su corta andadura desde que fue puesto al libre acceso de la ciudadanía. Para ello vamos a tener en cuenta los principios básicos que guían su actividad: 1/ primacía del archivo como un servicio público; 2/ puesta en práctica de la cultura de calidad; 3/ valoración de los usuarios.

Sin duda, la orientación al ciudadano es el objetivo estratégico principal de esta plataforma, siendo un factor clave la satisfacción de sus demandas, así como conocer su grado de satisfacción con los servicios prestados. Debido a ello sería conveniente que el Ministerio de Cultura llevase a cabo un proceso de evaluación externa a través de distintas encuestas sobre el grado de satisfacción de los usuarios respecto a PARES. En ellas debería primarse el análisis de los servicios que son prestados, su organización y funcionamiento, y por último su accesibilidad. Todo ello ayudaría a 
detectar posibles deficiencias, por lo que las mejoras podrían ser implantadas de un modo consciente y decidido. La importancia de consultar a los ciudadanos que utilizan esta herramienta es elemental para poder explicar el por qué de su decidida apertura a la sociedad de la información.

Atendiendo al tipo de servicio prestado se pueden diferenciar los siguientes grandes colectivos de demandantes de información:

- Usuarios que utilizan el archivo para la defensa de sus derechos. Son aquéllos que necesitan de algún documento realizado por la Administración Local. Los ciudadanos en la defensa de sus intereses y en sus múltiples relaciones con las administraciones necesitan en numerosas ocasiones documentos acreditativos que les permitan exhibir ciertos derechos que sin ellos no podrían ejercer.

- Usuarios que utilizan el archivo como investigadores. Se trata de los usuarios tradicionales de nuestros centros. Éstos acuden a los centros de archivo con el fin de realizar investigaciones de carácter científico o técnico consultando las fuentes documentales custodiadas en aquéllos. Dichos fondos son consultados tanto por profesionales de la investigación relacionados con el mundo universitario (historiadores, sociólogos, filólogos o alumnos de doctorado), como personas que dedican su tiempo libre a investigar sobre la historia de sus antepasados (encontrándonos con personal funcionario, profesores de secundaria y personas jubiladas).

- Usuarios que lo emplean para la docencia. Aparecen tanto profesores como estudiantes de enseñanzas primarias y secundarias, así como universitarias. En ambos casos utilizan los archivos por distintos motivos. Por un lado, los docentes tratan de mejorar y modernizar sus métodos pedagógicos para que los alumnos interactúen con las nuevas tecnologías y con el patrimonio documental. Mientras que los estudiantes se ven en la obligación de acceder a los fondos para confeccionar trabajos o elaborar tareas que les han encomendado en sus centros docentes (escuela o universidad).

- Usuarios que recurren al estudio de los fondos digitalizados por curiosidad. Estamos ante el grupo más numeroso en la actualidad. Se trata de personas que acuden a la consulta de los fondos que se encuentran digitalizados sin un objetivo concreto. Para este colectivo puede llegar a entenderse el servicio que presta PARES como un divertimento pasajero. Son la muestra inequívoca del proceso socialización de la cultura que se está experimentando en los últimos años.

Por otro lado, para diseñar un correcto plan de calidad a instaurar en cualquier archivo virtual deberemos tener en cuenta sus objetivos estratégicos, así es necesario resaltar que los que anhelará alcanzar son: proteger el patrimonio documental del Estado; orientar su servicio al ciudadano; servir a la cultura a través de fondos 
documentales y lograr la excelencia a nivel interno y externo como organización. Buena parte de todas estas metas organizativas las conseguirá satisfacer gracias a una correcta gestión de la tecnología disponible. Tanto es así que, la planificación y la estrategia de PARES tienen como base fundamental también la correcta protección y difusión del patrimonio documental. En ambos casos las nuevas tecnologías se erigen en una pieza de suma utilidad. Por un lado, la digitalización permite evitar el trasiego y uso excesivo de la documentación para ser consultada; mientras que por otro, se consigue reducir la realización de fotocopias de forma indiscriminada que ocasionan un rápido envejecimiento y deterioro del papel. Por tanto, la utilización de las nuevas tecnologías para conseguir gestionar la masa documental que actualmente se custodia en los archivos estatales es absolutamente indispensable.

No obstante, el creciente éxito de una herramienta como PARES se debe a los ambiciosos objetivos que éste persigue. Entre ellos nos encontramos:

- Actuar como un espacio virtual que permita garantizar la difusión del patrimonio.

- Permitir que los distintos profesionales puedan interoperar para que los archivos estatales puedan ser visibilizados a nivel internacional

- Facilitar la presencia de diferentes proyectos en materia archivística para que se puedan tejer relaciones estrechas con otras redes de archivos.

- Debe ser un sitio web donde se puedan desarrollar las buenas prácticas archivísticas.

- Tratar de homologar los servicios que son prestados por los distintos archivos estatales.

- Introducir contenidos que permitan el aprendizaje e-learning de los usuarios.

- Garantizar el acceso a los documentos digitalizados en los respectivos archivos del Estado.

Crear una herramienta que resulte accesible porque sea intuitiva es fundamental para los usuarios, puesto que gracias a un diseño eficaz podrán obtener los resultados deseados en un menor tiempo de espera. Pero a su vez, resulta elemental para la propia supervivencia del portal porque sus creadores deben tratar de fidelizar demandantes de información. Aspecto que se consigue si logran que un número importante de usuarios retornen de forma periódica al sitio web para seguir explotando los recursos que ofrecen. Mientras que por el contrario, si en una primera incursión no ven satisfechas sus exigencias optarán por no volver a consultar la página web. 
Tabla I. Evolución entre unidades descriptivas e imágenes ${ }^{26}$

\begin{tabular}{|c|c|c|}
\hline Año & Unidades descriptivas & Imágenes \\
\hline 2007 & 1.944 .413 & 12.983 .859 \\
\hline 2008 & 2.622 .973 & 13.560 .312 \\
\hline 2009 & 4.692 .611 & 17.477 .619 \\
\hline 2010 & 5.018 .347 & 24.321 .225 \\
\hline 2011 & 5.455 .109 & 26.435 .158 \\
\hline
\end{tabular}

Gráfico 1. Comparativa entre unidades descriptivas e imágenes

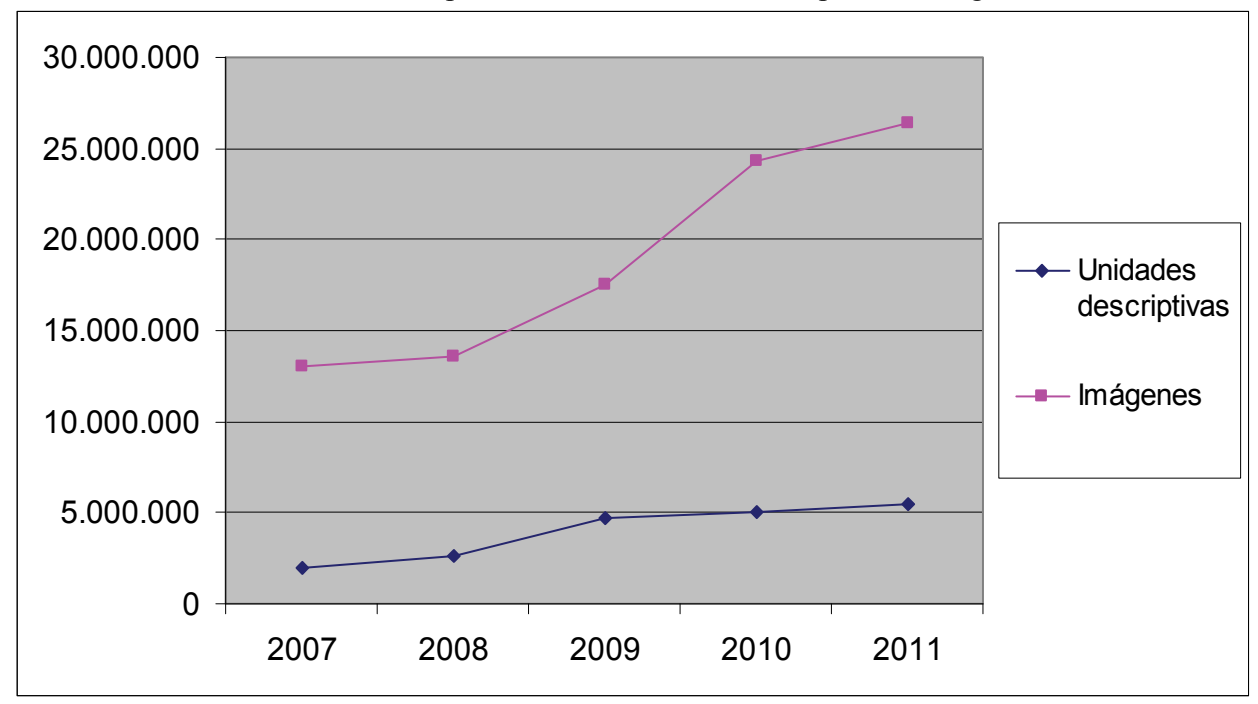

El crecimiento de PARES en los últimos cinco años ha puesto de manifiesto la decidida apuesta del gobierno estatal por la cultura digital. Tanto es así que, entre 2007 y 2011, el Portal de Archivos Españoles ha experimentado un aumento de los contenidos archivísticos que gestiona y difunde. Pero, ¿se trata de una herramienta eficaz? Es necesario medir tanto sus repercusiones cuantitativas como cualitativas, por lo que resulta conveniente analizar los distintos datos que nos aporta la difusión digital para comprobar el volumen de consultas que se han producido desde 2007. Momento, este último, en el que se puso en marcha PARES. Desde entonces el crecimiento experimentado por esta herramienta ha sido constante, resultando sumamente evidente si nos ponemos a examinar los datos contenidos en la tabla II, así como en los siguientes gráficos.

\footnotetext{
${ }^{26}$ Información facilitada por la Subdirección General de los Archivos Estatales, Área de Relaciones Institucionales.
} 
Tabla II. Estudio evolutivo del acceso a los archivos estatales ${ }^{27}$

\begin{tabular}{|c|c|c|c|c|c|c|}
\hline \multirow{2}{*}{ Año } & \multicolumn{2}{|c|}{$\begin{array}{c}\text { Número de usuarios } \\
\text { distintos }\end{array}$} & \multicolumn{2}{c|}{$\begin{array}{c}\text { Número de visitas/Sesiones de } \\
\text { trabajo }\end{array}$} & \multicolumn{2}{c|}{ Documentos consultados } \\
\cline { 2 - 7 } & Virtual & Presencial & Virtual & Presencial & Virtual & Presencial \\
\hline 2007 & 205.054 & 9.014 & 356.615 & 34.828 & 60.312 .871 & 281.406 \\
\hline 2008 & 367.641 & 7.112 & 626.684 & 33.609 & 104.085 .695 & 198.811 \\
\hline 2009 & 376.641 & 6.592 & 694.890 & 33.922 & 100.973 .329 & 189.622 \\
\hline 2010 & 461.176 & 7.775 & 843.783 & 33.184 & 106.377 .481 & 155.257 \\
\hline 2011 & 474.348 & 7.810 & 923.814 & 30.333 & 107.426 .370 & 140.764 \\
\hline
\end{tabular}

El éxito de PARES es evidente si nos ponemos a comparar las distintas variables que se han puesto de manifiesto. Así, por ejemplo, las altas de usuarios sí que pueden haber disminuido debido al efecto de PARES. En 2003, según la base de datos estadística CULTURAbase $^{28}$, se cifraron en 9.947 las altas, para aumentar en los años siguientes: 2004 (10.137) y 2005 (10.018). Posteriormente comenzó un acusado descenso en 2006 (9.271) que se mantuvo, e incluso se incrementó a partir de 2007 (9.014). Para descender de forma brusca en 2008 (7.112), y sobre todo en 2009 (6.592), aunque en 2010 (7.775) y 2011 (7.810) se recuperaron altas que arrojan cierta esperanza en el acceso presencial. Frente a ellos nos encontramos con los usuarios que han accedido de forma virtual a los archivos estatales desde 2007. Así desde los iniciales 205.054 que se dieron de alta en el primer año de funcionamiento del portal se ha constatado un incremento anual paulatino, ya que en 2008 fueron 367.641, en 2009 un total de 376.641, y ya en 2010 crecieron hasta los 461.176, siendo superados por los 474.348 de 2011.

Gráfico 2. Evolución en el número de usuarios según modalidad

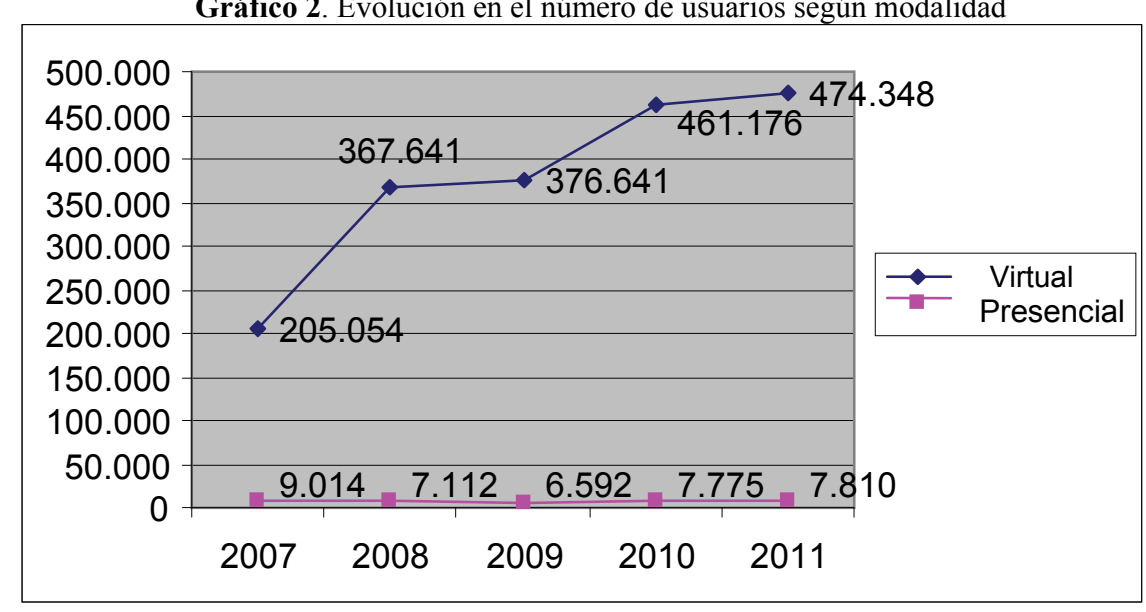

${ }^{27}$ Tabla de elaboración propia.

${ }^{28}$ Véase http://www.mcu.es/culturabase/cgi/um?M=/t15/p15/a2005/\&O=pcaxis\&N=\&L=0. Estadísticas sobre Archivos de titularidad Estatal. Consultado el 15 de diciembre de 2012. 
No contamos con los datos de 2012 porque todavía no están disponibles hasta que se proceda a elaborar la memoria anual a principios de este año. Pese a ello, la tendencia sigue mostrando una línea similar, contribuyendo a afianzar las expectativas de PARES y sentando las bases para las próximas décadas. Pero sí se comprueba que, entre 2007 y 2011, asistimos a una evidente fractura entre los tipos de usuarios que existen en la actualidad. PARES ha roto con la dinámica de los ciudadanos que asistían a los archivos de modo presencial. En los cinco años que lleva funcionando el portal -puesto que los datos de 2012 todavía no se conocense ha puesto de manifiesto que el $98 \%$ de los usuarios fueron virtuales, ante el $2 \%$ que optaron por acceder de forma presencial.

Gráfico 3. Comparativa entre el tipo de usuarios

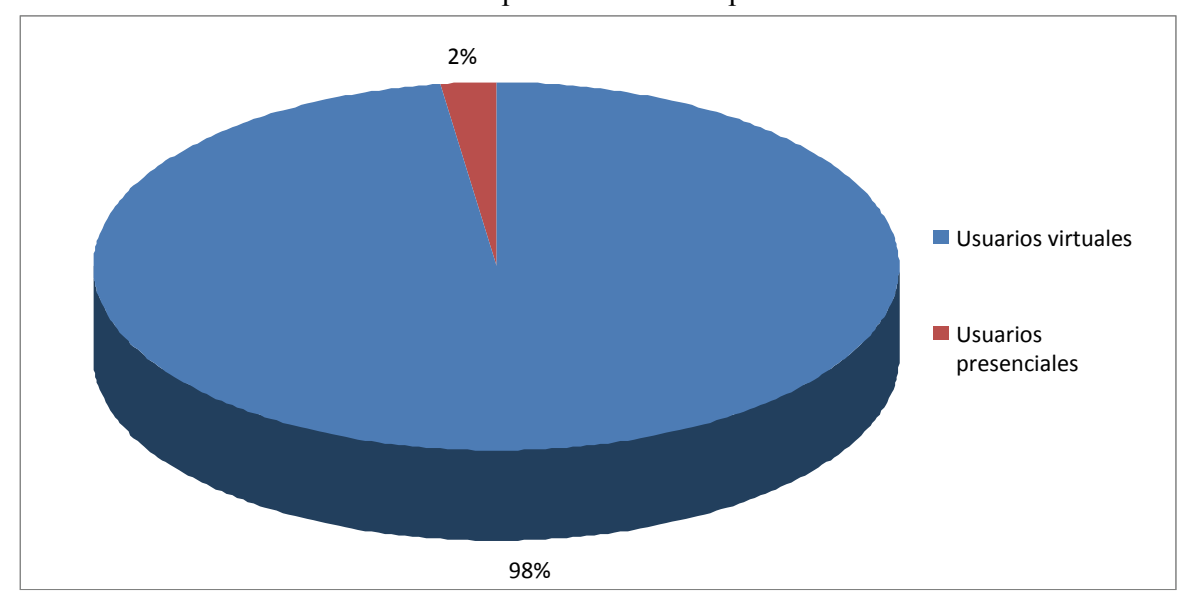

Gráfico 4. Evolución en el número de sesiones según la modalidad

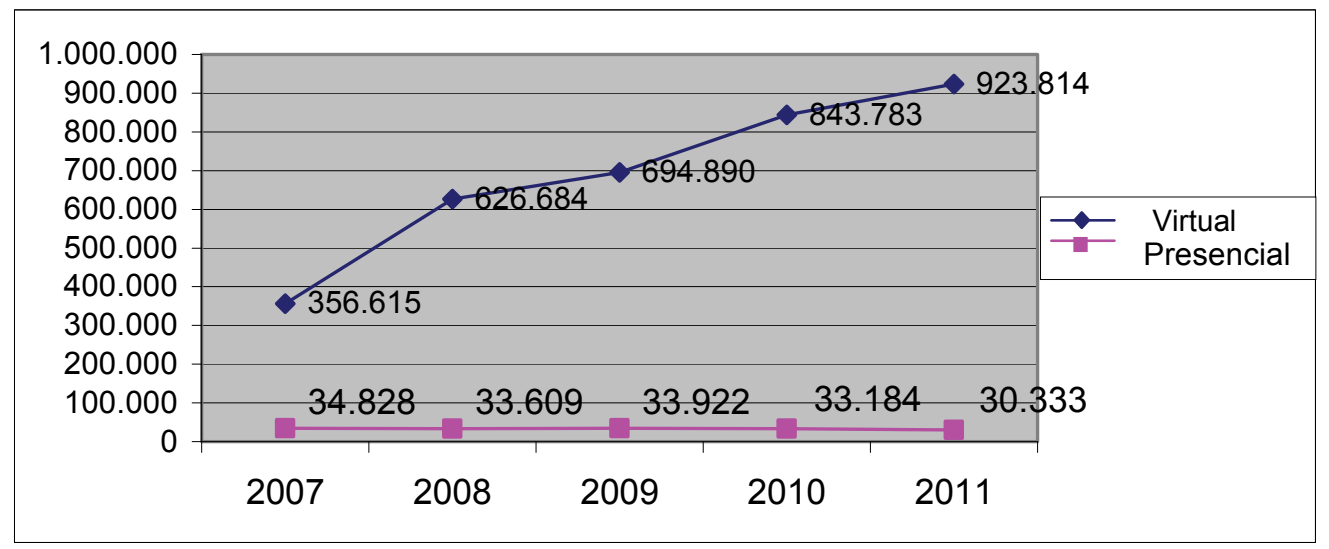

A su vez, la disminución de los usuarios presenciales y el considerable aumento de los virtuales ha supuesto un cambio en el modo de llevar a cabo las sesiones 
de trabajo. El descenso presencial ya venía de antes, porque el Ministerio de Cultura a través de CULTURAbase ${ }^{29}$ muestra que el acceso presencial a los archivos de titularidad estatal comenzó a decrecer a partir de 2003 (39.522). A partir de entonces se produjo un descenso continuado: 2004 (39.422), 2005 (37.774) y 2006 (36.661). Aunque fue en 2007, coincidiendo con la puesta en marcha de PARES, cuando se experimentó un descenso más acusado. En aquel año se contabilizaron un total de 34.828 sesiones de trabajo presenciales, las cuales han ido disminuyendo poco a poco con el paso de los años: 2008 (33.609), 2009 (33.922), 2010 (33.184) y 2011 (30.333).

Bien es cierto que, cabe la posibilidad de que dicho proceso no se haya originado fruto de la aparición de PARES. Puede que una pequeña porción sí, pero las explicaciones son de mayor calado. Es posible que la falta de interés de la gente, o de tiempo, así como los horarios de apertura hayan dificultado la consulta presencial de los documentos. Sin embargo, las sesiones de trabajo que se han llevado a cabo de forma virtual no dejan de crecer. En estos cinco años que se han contabilizado del funcionamiento del portal se han registrado 3.445.786 sesiones. Desde las 356.615 que se produjeron en 2007 hasta las 923.814 de 2011.

Si comparamos el tipo de sesiones de trabajo que llevan a cabo los usuarios que acceden a los archivos estatales comprobamos que durante 2007-2011 el 95\% de estas sesiones se produjeron de modo virtual utilizando el Portal de Archivos Estatales, mientras que el $5 \%$ de dichas sesiones fueron presenciales. Constatándose, nuevamente, el triunfo de PARES frente a los modos y prácticas investigadoras más tradicionales.

Gráfico 5. Comparativa entre los diferentes tipos de sesiones

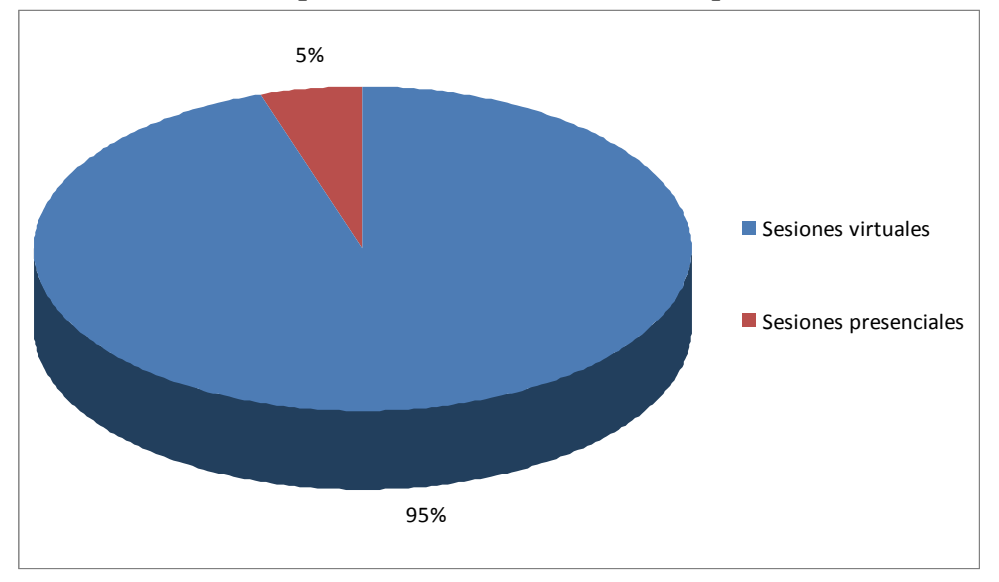

${ }^{29}$ Véase http://www.mcu.es/culturabase/cgi/um? M=/t15/p15/a2005/\&O=pcaxis\&N=\&L=0. Estadísticas sobre Archivos de titularidad Estatal. Consultado el 15 de diciembre de 2011. 
No cabe duda de que el paulatino descenso en las visitas presenciales ha provocado una considerable merma en la consulta de documentos originales en los archivos, cuya cifra ha ido en franco retroceso desde 2007. Lo que no quiere decir que el uso de los archivos sea menos intenso, a pesar de que los usuarios y el tiempo libre para la investigación han disminuido en la última década. En los cinco años que han pasado desde que se lanzó PARES se han pedido un total de 965.860 documentos de forma presencial, una cifra que no puede compararse con los 479.175.749 que han sido examinados gracias a las imágenes digitales que se albergan en las bases de datos del portal. Desde 2007 (281.406) se constata un evidente descenso en el número de documentos que son consultados presencialmente, tendencia que se confirma en los años posteriores; 2008 (198.811), 2009 (189.622), 2010 (155.267) y 2011 (140.764). Todo lo contrario a los documentos analizados virtualmente, los cuales crecen exponencialmente a partir de 2007 (60.312.871), aunque será en los años siguientes cuando se registre un mayor aumento: 2008 (104.085.695), 2009 (100.973.329), 2010 (106.377.481) y 2011 (107.426.370).

Gráfico 6. Evolución en el número de documentos consultados según modalidad

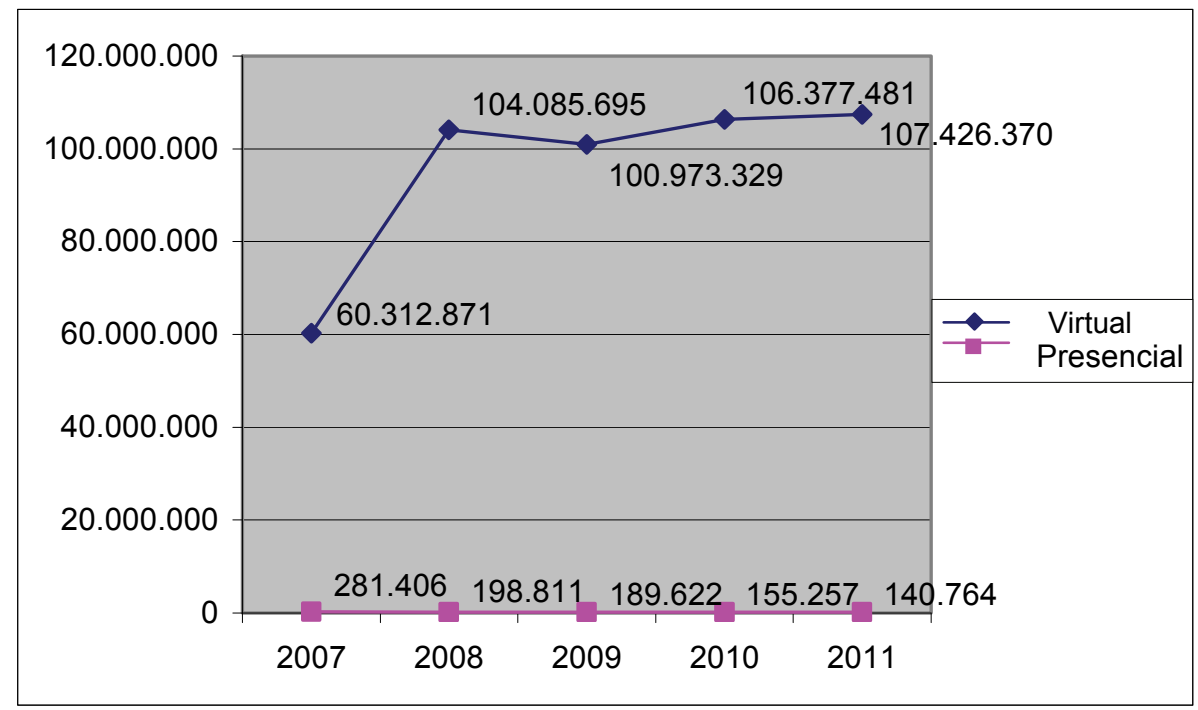


Gráfico 7. Comparativa entre el modo de consulta de documentos

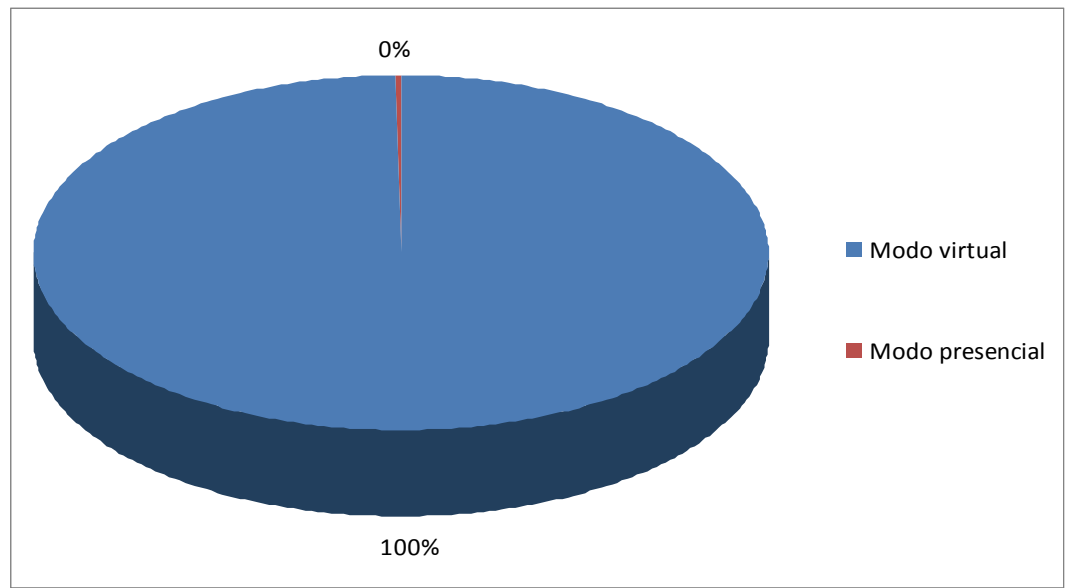

Es en la consulta de documentos donde se aprecia el ritmo voraz que ha supuesto la puesta en marcha del Portal de Archivos Españoles, puesto que entre 2007 y 2011 el $99.9 \%$ de los documentos se han consultado de un modo virtual, y únicamente el $0.1 \%$ lo han sido de modo presencial. Esta enorme diferencia obedece a las múltiples facilidades que oferta PARES, ya que pueden ser consultados una infinidad de documentos digitalizados al mismo tiempo, mientras que en los archivos el número de éstos que pueden pedirse de una vez está restringido. Además, hasta que no son devueltos no pueden consultarse otros distintos.

Se observa claramente como el acceso virtual a través del Portal de Archivos Españoles ha experimentado un considerable aumento respecto al presencial a las Salas de Investigación de la red de archivos estatales. No obstante, los investigadores profesionales suelen acceder en distintos momentos de su proceso de indagación a consultar los documentos originales. Los datos ponen de manifiesto que el número de usuarios que acceden presencialmente a los fondos de archivo ha sufrido un considerable descenso. Lo que también se ve corroborado por el ligero descenso que han sufrido el número de sesiones de trabajo presencial y las consultas de documentos. Bien es cierto que no todas estas variables han sufrido un descenso proporcional, pero sí evidencian una tendencia que sigue una misma pauta, el descenso de los accesos y usos de los servicios de manera física por los ciudadanos en los archivos estatales.

Lo que no quiere decir que aquellos que acuden a los archivos no realicen un uso mucho más eficiente en sus visitas, ya que gracias a PARES pueden traer el trabajo hecho previamente porque les permite realizar búsquedas y localizar los documentos que van a necesitar. Ello hace que puedan economizar el tiempo que están en el archivo consultando los documentos que requieren porque se evitan la consulta a los distintos instrumentos de descripción tradicionales, pues el portal da 
la opción de efectuar consultas en línea sobre un inventario conformado por más de 5.5 millones de fichas descriptivas.

\section{CONCLUSIONES}

Duchein hizo mención a la sed de la sociedad por acceder al patrimonio existente en los archivos, aseverando que para conocer el pasado no había medio más eficiente, puesto que "el más humilde documento de un archivo local constituye un testimonio irremplazable, permite escuchar una voz al mismo tiempo lejana y familiar que no se sabría encontrar en otra parte" ${ }^{30}$. Resulta evidente que los archivos se muestran como los garantes de la memoria de una sociedad. Bien es cierto que, en la actualidad, esta capacidad se está equiparando con su función pedagógica. Así la inmensa masa de documentos que atesoran los centros de archivo sirve para permitir a la ciudadanía disponer de la información que precisa de un modo rápido y eficiente. Y más, teniendo en cuenta que los servicios que debe ofertar el archivo en el siglo XXI deben estar orientados hacia una sociedad que trata de satisfacer sus demandas de información, exigiendo cada vez una mejora evidente en los productos y materiales que muestran dichos centros.

En la actualidad hay un creciente interés por parte de la sociedad por lograr ampliar sus conocimientos, por lo que los archivos se muestran como el escaparate idóneo a través del cual poder satisfacer las necesidades ciudadanas. Y qué mejor forma de publicitar los servicios de los archivos que aprovecharnos de los beneficios que nos aporta Internet. No puede existir un medio más eficaz para llegar a un público cada vez más amplio. Por ello debemos tender hacia el archivo virtual, pero no sólo para instruir a la población en valores de respeto y divulgación del patrimonio cultural, sino también para formar a las nuevas generaciones. En definitiva, de este trabajo se desprende la idea de que el servicio que todo archivo debe prestar a la sociedad actual gira en torno al uso y aplicación de las nuevas tecnologías como medios de difusión y comunicación para gestionar de un modo eficaz el patrimonio documental.

De la mano de las nuevas tecnologías, el acceso a la información existente en los archivos ha provocado que se hayan originado toda una serie de cambios, caso de las mejoras introducidas en las descripciones, las novedades en el campo de la conservación de los documentos, e incluso ha surgido un nuevo tipo de usuarios que consumen los servicios que son ofertados en los archivos. Pese a ello, el cambio más sustancial se ha sucedido en el acceso a los documentos. Como sugiere

${ }^{30}$ DUCHEIN, M., "Prefacio", ALBERCH, R.; BOADAS, J. (eds.), La función cultural de los archivos. Bergara, 1991, p. 14. 
Latorre Merino $^{31}$, la apuesta decidida de algunas organizaciones e instituciones por mostrar su patrimonio documental en la red ha hecho que se configure una enorme área de lectura, en donde los problemas de horarios y de desplazamientos físicos son inexistentes.

Como se ha puesto de manifiesto en el presente estudio los centros de archivo deben abrirse al exterior, prestando así un servicio a la comunidad. En ello va a desempeñar un papel principal Internet, puesto que la red, en principio, se encuentra disponible a nivel mundial, por lo que será la sociedad de la información a la que se le ofrezca la ingente masa de documentos custodiados en los archivos. Es evidente que las nuevas tecnologías han supuesto una auténtica revolución en el campo de la archivística al aproximar al ciudadano a los centros de archivo gracias al acceso on-line. No obstante, como ya hemos señalado a lo largo de este trabajo, nos encontramos frente a nuevos retos que debemos ser capaces de asumir con rotundidad. Me estoy refiriendo a la adopción de un modo decidido de las técnicas de la web 2.0, convirtiendo a la ciudadanía no sólo en consumidora de servicios, sino en parte implicada de un proceso de comunicación que tiene que hacer de la cultura un bien de todos y para todos.

Fruto de este nuevo paradigma comunicacional debemos tratar de atender a todos los usuarios por igual, aunque será conveniente llamar la atención de un espectro poblacional que no acude a los archivos porque no son de su interés, o que únicamente acuden a ellos de un modo testimonial para conseguir alguna información. Conseguir implicar a nuevos usuarios debe ser nuestra meta. Dicha propuesta, aunque suene ambiciosa, es factible si sabemos aprovechar la estela marcada por las nuevas tecnologías de la información. Gracias a ellas conseguiremos acercar nuestros centros de archivo a los potenciales usuarios que deseen hacer uso de sus servicios a través de la web. Pero no sólo esto, porque si gestionamos de un modo eficiente lo que ha dado en llamarse como la web 2.0 y otras realidades como las redes sociales, seremos capaces de multiplicar exponencialmente nuestra presencia en la sociedad. Es decir, conseguiremos estar visibles a los demás. La publicidad que nos ofrecen estos nuevos mecanismos de comunicación será nuestro mejor aliado. Pese a lo que seremos nosotros los encargados de saber gestionarla de un modo coherente y eficaz.

Tal y como hemos constatado en este estudio, para atender a los distintos tipos de usuarios que nos vamos a encontrar en la actualidad tendremos que acomodarnos y servir fielmente a sus demandas. Esta debe ser nuestra meta, esforzarnos por ofertar un buen servicio a la sociedad ${ }^{32}$. Clave en este proceso debe ser la concepción de

${ }^{31}$ LATORRE MERINO, J. L., “Archivo y tecnología. Análisis de los cambios producidos en los archivos con la incorporación de las tecnologías de la información y la comunicación", REY DE LAS PEÑAS, R. (dir.), Los nuevos paradigmas de la archivística. Huelva, 2009, p. 42.

${ }^{32}$ TORREBLANCA LÓPEZ, A., "El archivo como servicio público". Boletín de la ANABAD, LII-3, 2002, p. 103. 
nuestra profesión como un servicio a la ciudadanía, por lo que los archivos en la sociedad de la información deben pivotar sobre esta realidad ${ }^{33}$.

De la misma manera, se ha comprobado que las tecnologías de la información están teniendo un impacto muy positivo sobre el patrimonio documental, y más teniendo en cuenta que los sistemas informáticos permiten gestionar de forma automatizada determinadas funciones que se desarrollan en los centros de archivo. Lo que contribuye, y contribuirá, a mejorar el servicio ofertado a los usuarios. Manifestándose dicho extremo en diversos aspectos, caso de la reducción en el tiempo de necesario para identificar y localizar los documentos pertinentes. Todo ello gracias, en buena medida, a las búsquedas que pueden efectuarse con las bases de datos descriptivas. Además, todo esto permite reducir el tiempo de espera para la consulta de los documentos que se decidan examinar. En suma, la digitalización es en estos momentos la mejor solución para la preservación de los documentos originales, lo que también contribuye a garantizar el acceso a la información existente en nuestros archivos. Por ello, abordar la reproducción digital de los documentos para hacerlos asequibles de forma virtual a un mayor número de usuarios se erige como una manera inmejorable de combinar dos conceptos. Primero, cómo poner la documentación al servicio de la sociedad de la información en la que nos encontramos inmersos, y en segundo lugar, permite conservar el patrimonio documental para las generaciones venideras.

En definitiva, el presente artículo ha logrado constatar que PARES es un proyecto de un elevado valor cultural que facilita que interactúen la divulgación y la erudición científica. Todo ello, gracias a las nuevas tecnologías. Evidenciándose que dicho proyecto no sólo tiene como fin la preservación de los documentos originales evitando su uso, sino que otro de sus pilares elementales es proyectarse a la sociedad, promoviendo la difusión del patrimonio documental del Estado. Este nuevo paradigma ha provocado un tsunami en nuestra disciplina y únicamente nos queda adaptarnos a los nuevos tiempos que llegan para asumir los retos que nos plantea la sociedad del siglo XXI. Planteamientos a los que sí ha sabido dar respuesta PARES, por lo que debemos concebirlo como el garante del cambio en nuestro país y como uno de los más firmes impulsores de esta nueva realidad en el continente europeo.

Una novedosa etapa que, como se ha constatado en este trabajo, está siendo posible gracias al Portal de Archivos Españoles, y más si tenemos en cuenta los datos que se han conseguido obtener en esta investigación en relación con el acceso a nuestros archivos. Lo que nos permite hacer las siguientes consideraciones:

- La apuesta por la gestión y la difusión electrónica ha aumentado la visibilidad del mundo de los archivos españoles entre la comunidad internacional.

${ }^{33}$ PIRES DE LIMA, M. J., “DIGITARQ: del archivo digital al usuario”. Tabula, 8, 2005, p. 52. 
- Se ha producido un ligero descenso en el número de investigadores presenciales en las salas de los archivos.

- El aumento de usuarios virtuales es considerable desde que se puso en funcionamiento el portal, aunque es llamativo el incremento experimentado a partir del año 2008.

- El volumen de descripciones llevadas a cabo ha asistido a un aumento exponencial desde 2007. Ello pone de manifiesto que se trata de una tarea crucial para el devenir de la plataforma, ya que sin ellas los usuarios no podrían recuperar la información requerida.

- El número de imágenes que albergan las bases de datos existentes en PARES ha crecido a un ritmo vertiginoso, pasando de los 12.983 .859 que había a finales de 2007 hasta los 28.235.158 que llevan en septiembre de 2012.

- Las sesiones de trabajo han sufrido una ligera alteración, ya que las consultas presenciales se han reducido en casi 5.000 entre 2007 y 2011, mientras que los accesos virtuales sobrepasan las 900.000 .

- Los documentos que son consultados presencialmente descienden, pero lo llamativo es el ingente aumento que se ha evidenciado en el número total de documentos examinados a través de Internet, alcanzándose unas cifras para 2011 de 107.426.370.

Por todo ello, considero que los datos examinados en el presente artículo ponen de manifiesto el rotundo éxito que ha supuesto PARES en su corta andadura. Desde 2007 ha ido ratificando la firme apuesta que llevó a cabo el Ministerio de Cultura $^{34}$, y tras cinco años se ha constatado que se trata de una herramienta eficaz para la ciudadanía. Considero que los resultados registrados evidencian el inicio de una nueva etapa en las relaciones entre la sociedad y los centros de archivo. En este nuevo paradigma comunicacional en el que estamos inmersos el triunfo de las nuevas tecnologías es tan evidente que hasta nuestra disciplina se ha visto abocada al cambio debido al dominio ejercido por las mismas.

\section{REFERENCIAS BIBLIOGRÁFICAS}

ALBERCH, R., "Memoria, digitalización y mecenazgo", El profesional de la información, 10, 9, 2001, pp.34-36.

ANGULO MORALES, A., "Algunas reflexiones sobre los recursos de archivos históricos en Internet y en la enseñanza de la Historia”, Hispania, LXVI, 222, 2006, pp. 31-58.

${ }^{34}$ En la actualidad se denomina Ministerio de Educación, Cultura y Deporte. 
ANORVE GUILLÉN, M. A., "Archivos y sociedad”, Revista general de información y documentación, 17-2,2007, pp. 123-128.

BARROSO, A., "Archivos virtuales: ¿ya hemos llegado? El proyecto de digitalización del AHEB-BEHA", Letras de Deusto, 33-II, 100, 2003, pp. 53-67.

BESCÓS, J.; NAVARRO, J., "El documento histórico y el impacto de las tecnologías de la información", Congreso Internacional sobre Sistemas de Información Histórica, Álava, Juntas Generales de Álava, 1997, pp. 103-117.

BESCÓS, J.; NAVARRO, J., "La digitalización como medio para la preservación y acceso a la información en archivos y bibliotecas", Educación y bibliotecas. Revista mensual de Documentación y recursos didácticos, 80, 1997, pp. 28-41.

CERDÁ DÍAZ, J., "Archivos locales en la web. El futuro en la red", J. J. Morales Gómez (coord.), Actas de las VIII Jornadas de Archivos Aragoneses. Compartir Archivos, Vol. II, Huesca, Gobierno de Aragón, 2008, pp. 151-171.

CERDA DÍAZ, J., "Archivos y educación en la era digital. Nuevas vías de acceso y difusión para los servicios de archivo", R. Rey de las Peñas (dir.), Aprender y enseñar con el archivo, Huelva, Diputación Provincial de Huelva, 2004, pp. 47-75.

DE LA OSSA DÍAZ, F., "Reproducción de documentos y conservación del patrimonio documental", Boletín de la ANABAD, LII, 3, 2002, pp. 21-82.

DUCHEIN, M., "Prefacio", Alberch, R.; Boadas, J. (eds.), La función cultural de los archivos, Bergara, Irargi. Centro de Patrimonio Documental de Euskadi, 1991, pp. 14-15.

ECHEVERRÍA, J., "Cultura digital y memoria en red", Arbor. Ciencia, Pensamiento y Cultura, CLXXXV, 737, 2009, pp. 559-567.

ESCALANTE JIMÉNEZ, J., "El Archivo Histórico Municipal de Antequera: conservación y perspectivas de futuro", Sociedad: Boletín de la Sociedad de Amigos de la Cultura de Vélez-Málaga, 4, 2005, pp. 35-38.

ESTEPA JIMÉNEZ, J., "El patrimonio documental y los archivos como recursos en la enseñanza de las ciencias sociales", R. Rey de las Peñas (dir.), Aprender y enseñar con el archivo, Huelva, Diputación Provincial de Huelva, 2004, pp. 33-45.

FERNÁNDEZ IZQUIERDO, F., "Fuentes primarias: la documentación archivística en Internet", A. Maldonado Martínez; L. Rodríguez Yunta (coords.), La información especializada en Internet, Madrid, CSIC, 2006, pp. 387-422.

FERNÁNDEZ IZQUIERDO, F., "Investigar, escribir y enseñar Historia en la era de Internet", Hispania, LXVI, 222, 2006, pp. 11-30.

HERNÁNDEZ OLIVERA, L., "La ley del deseo: un examen a las medidas adoptadas por el Gobierno para cumplir la ley de Restitución de documentos a la Generalidad", Archivamos, 63, 2007, pp. 7-10.

HUIDOBRO, J. M., "La sindicación web: RSS", Bit, 167 (2008), pp. 58-61.

IGARZA, R., Burbujas de ocio. Nuevas formas de consumo cultural, Argentina, La Crujía, 2009. 
LATORRE MERINO, J. L., "Archivo y tecnología. Análisis de los cambios producidos en los archivos con la incorporación de las tecnologías de la información y la comunicación", Rey de las Peñas, R. (dir.), Los nuevos paradigmas de la archivística, Huelva, Diputación Provincial de Huelva, 2009, pp. 35-48.

MUÑOZ, P., "Implementación del formato RSS en procesos de gestión y comunicación electrónicos en instituciones educativos, públicas y empresariales", Pixel-Bit, 31, 2008, pp. 5-18.

PIRES DE LIMA, M. J., "DIGITARQ: del archivo digital al usuario", Tabula, 8, 2005, pp. 43-53.

RIVAS FERNÁNDEZ, J. B., "La sociedad del ocio: un reto para los archivos", Códice, 2-2, 2006, pp. 71-82.

SÁNCHEZ, N., "Sindicación de contenidos con canales RSS: aplicaciones actuales y tendencias", Acimed, 15-3, 2007.

SÁNCHEZ MAIRENA, A., "Acercando los archivos a los ciudadanos. Una experiencia desde el Portal de Archivos Españoles (PARES) del Ministerio de Cultura", Arbor, 752, 2012, pp. 3-21.

SÁNCHEZ MAIRENA, A., "El Portal de Archivos Españoles (PARES) como recurso para la historia local en internet", Canelobre. Revista del Instituto Alicantino de Cultura Juan Gil - Albert, 58, 2011a, pp. 73-82.

SÁNCHEZ MAIRENA, A., "Nuevos retos en PARES (Portal de Archivos Españoles): interoperabilidad, normalización y calidad descriptiva y eficiencia del acceso al patrimonio archivístico digital español", VV.AA. (eds.), Actas del seminario internacional el futuro de la memoria: el patrimonio archivístico digital, Santiago de Compostela, Xunta de Galicia, 2011b, pp. 783-801.

SEBASTIÀ I SALAT, M., "Archiveros/Infotecnólogos: la Internet como motor del cambio de imagen de los archivos", XII Jornadas de Archivos Municipales. El Archivo en el Entorno Cultural, Madrid, Consejería de Cultura de la Comunidad de Madrid, 1998, pp. 91-112.

TORREBLANCA LÓPEZ, A., "El archivo como servicio público", Boletín de la $A N A B A D$, LII, 3, 2002, pp. 95-106.

TORRES FREIXINET, L., "Preservación digital, el reto del futuro", J. J. Morales Gómez (coord.), Actas de las VIII Jornadas de Archivos Aragoneses. Compartir Archivos, Vol. II, Huesca, Gobierno de Aragón, 2008, pp. 75-93. 